\title{
Avaliação da temperatura, turbidez e pH no Córrego das Marrecas - SP
}

Evaluation of temperature, turbidity and $\mathrm{pH}$ in Stream of Marrecas - SP

Evaluación de la temperatura, turbidez y pH en el Corriente de las Marrecas - SP

Osmar Pereira da Silva Junior

Mestrando, UNESP - Ilha Solteira/SP, Brasil engosmar1992@gmail.com

Sérgio Luís de Carvalho

Professor Doutor, UNESP, Brasil sergicar@bio.feis.unesp.br

Bruna Ragassi

Mestranda, UNESP - Ilha Solteira/SP, Brasil bruna_ragassi@hotmail.com 


\section{RESUMO}

Nos últimos anos os recursos hídricos vêm sendo modificados por ações antrópicas, resultando em prejuízo na qualidade e disponibilidade de água. Portanto, este trabalho se propôs a analisar, durante seis meses (abril de 2017 a setembro de 2017) os parâmetros temperatura, turbidez e pH na água do Córrego das Marrecas no município de Dracena - SP. A avaliação do Córrego em relação ao parâmetro turbidez demonstrou que é necessário continuar o monitoramento para verificar se o resultado discrepante obtido no ponto 3 no mês de setembro foi um episódio isolado ou um valor que começaria a ser comum em futuras analises. O monitoramento continuo do parâmetro pH poderá evidenciar se no período chuvoso os valores tenderiam a aumentar, constatando qual a faixa de variação sazonal deste parâmetro. , permitindo assim verificar se essa variação poderia estar afetando algum organismo ou reação química. A necessidade de monitorar os valores dos resultados do parâmetro temperatura da água na estação chuvosa é de suma importância para verificar a variação sazonal, uma vez que a temperatura tem reflexos sobre a vida aquática As elevações de temperatura aumentam a taxa das reações químicas e biológicas, aumenta também a taxa de transferência dos gases, o que pode causar mau cheiro e diminuem a solubilidade dos gases. Portanto, o monitoramento dos parâmetros analisados deve continuar para constatar as variações que podem ocorrer em um período de tempo maior.

Palavras - chave: Qualidade da água. Águas superficiais.

\section{ABSTRACT}

In recent years water resources have been modified by anthropic actions, resulting in impairment in water quality and availability. Therefore, this work has proposed to analyze, for six months (April 2017 to September 2017) the parameters temperature, turbidity and $\mathrm{pH}$ in the Stream of Marrecas water in the municipality of Dracena - SP. The evaluation of the mackerel stream in the municipality of Dracena - SP in relation to the turbidity parameter showed that it is necessary to continue the monitoring to verify if the discrepant result obtained in point 3 in the month of September was an isolated episode or a value that would start to be common in future analyzes. The continuous monitoring of the $\mathrm{pH}$ parameter can show if in the rainy period the $\mathrm{pH}$ values tend to increase, verifying the seasonal $\mathrm{pH}$ variation range. It can then verify if this variation could be affecting some organism or chemical reaction. The need to monitor the values of the results of the temperature parameter of the water in the rainy season is of paramount importance to verify the seasonal variation, since the temperature has reflexes on the aquatic life, The elevations of temperature increase the rate of the chemical and biological reactions, also increases the rate of gas transfer, which can cause bad smell and decrease the solubility of the gases. Therefore, the monitoring of the analyzed parameters must continue to verify the variations that can occur in a larger period of time.

Key words: Water quality. Surface water.

\section{RESUMEN}

En los últimos años los recursos hídricos vienen siendo modificados por acciones antrópicas, resultando en perjuicio en la calidad y disponibilidad de agua. Por lo tanto, este trabajo se propuso analizar, durante seis meses (abril de 2017 a septiembre de 2017) los parámetros temperatura, turbidez y pH en el agua Corriente de las Marrecas en el municipio de Dracena - SP. La evaluación del Corriente de las mareas en el municipio de Dracena - SP en relación al parámetro turbidez demostró que es necesario continuar el monitoreo para verificar si el resultado discrepante obtenido en el punto 3 en el mes de septiembre fue un episodio aislado o un valor que comenzaría a ser común en futuros análisis. El monitoreo continuo del parámetro $\mathrm{pH}$ puede evidenciar si en el período lluvioso los valores del pH tenderían a aumentar, constatando cuál es el rango de variación estacional del pH. Por lo tanto, puede comprobar si esta variación podría estar afectando a algún organismo o reacción química. La necesidad de monitorear los valores de los resultados del parámetro temperatura del agua en la estación lluviosa es de suma importancia para verificar la variación estacional, una vez que la temperatura tiene reflejos sobre la vida acuática, las elevaciones de temperatura aumentan la tasa de las reacciones químicas y biológicas, aumenta también la tasa 
de transferencia de los gases, lo que puede causar mal olor y disminuir la solubilidad de los gases. Por lo tanto, el monitoreo de los parámetros analizados debe continuar para constatar las variaciones que pueden ocurrir en un período de tiempo mayor.

Palabras clave: Calidad del agua. Aguas superficiales. 


\section{INTRODUÇÃO}

Nos últimos anos os recursos hídricos vêm sendo modificados por ações antrópicas, resultando em prejuízo na qualidade e disponibilidade de água, por isso é imprescindível à necessidade do monitoramento das alterações nos parâmetros que determinam a qualidade dos corpos hídricos.

O conhecimento da qualidade da água disponível é fundamental para a gestão dos recursos hídricos. Sendo assim, existem vários índices e indicadores ambientais para avaliação destes recursos, tendo como base as suas características físico-químicas e biológicas (BARRETO, 2013).

Existem diversas maneiras de se avaliar a qualidade da água nos corpos hídricos, dentre elas as análises físico-químicas se destacam e são largamente utilizadas como parâmetros indicadores da qualidade. A resolução CONAMA 357/2005 é a normativa que estabelece os limites dos parâmetros físicos e químicos de corpos hídricos.

Os parâmetros físicos avaliados nesse trabalho foram temperatura e turbidez, enquanto como parâmetro químico foi avaliado o parâmetro $\mathrm{pH}$.

A temperatura é um dos parâmetros, ou características organolépticas, de qualidade das águas atrelada à sensibilidade dos organismos vivos, que tornam uma água atraente ou não para o consumo.

Quando a alteração da temperatura de um corpo hídrico é tão significativa a ponto de alterar a sua qualidade, a mesma passa a ser caracterizada como poluição térmica (PERCEBON; BITTENCOURT; FILHO, 2005).

As variações de temperatura são parte do regime climático normal e corpos de água naturais apresentam variações sazonais e diurnas, bem como estratificação vertical. A temperatura superficial é influenciada por fatores tais como latitude, altitude, estação do ano, período do dia, taxa de fluxo e profundidade (SILVA; ARAUJO, 2017). A elevação da temperatura em um corpo d'água geralmente é provocada por despejos industriais (indústrias canavieiras, por exemplo) e usinas termoelétricas (CETESB, 2009).

A turbidez é a interferência à passagem da luz através da água, causada por partículas insolúveis de solo, matéria orgânica, microorganismos e outros materiais, que desviam e/ou absorvem os raios luminosos que penetram na água RODRIGUES JUNIOR (2008). A turbidez é agravada pela presença de sólidos em suspensão na água, como argila, silte, substâncias orgânicas finamente divididas, organismos microscópicos e outras partículas provenientes de despejos domésticos e industriais, cuja precipitação perturba o ecossistema aquático (BRANCO, 1983).

O ph é a medida da concentração relativa de íons de hidrogênio numa solução; esse valor indica a acidez ou alcalinidade da solução. É calculado como o logaritmo negativo de base 10 da concentração de íons de hidrogênio em moles por litro. Um valor de pH 7 indica uma solução neutra; índices de pH maiores que 7 são básicos, e os abaixo de 7 são ácidos. A faixa 
de $\mathrm{pH}$ é de 0 a 14. Pode ser de origem natural através da dissolução de rochas, absorção de gases da atmosfera, oxidação da matéria orgânica e fotossíntese. Pode ter origem antropogênica, através de despejos domésticos RODRIGUES JUNIOR (2008). Segundo Lima (2001), o pH da grande maioria dos corpos d'água varia entre 6 e 8.

As medidas de $\mathrm{pH}$ são de extrema utilidade, pois fornecem inúmeras informações a respeito da qualidade das águas. As variações deste parâmetro ocorrem geralmente pelo consumo e/ou produção de dióxido de carbono $\left(\mathrm{CO}_{2}\right)$, realizados pelos organismos fotossintetizantes e pelos fenômenos de respiração-fermentação de todos os organismos presentes na massa d'água, produzindo ácidos orgânicos fracos (BRANCO, 1986). De acordo com Sperling (1996), a variação do $\mathrm{pH}$ pode ter origem natural (dissolução de rochas, absorção de gases, oxidação de matéria orgânica e fotossíntese) e/ou origem antropogênica (despejos domésticos e despejos industriais).

Segundo Maier (1987) uma pequena diminuição no pH pode estar associado ao aumento no teor de matéria orgânica que leva a consequente queda na quantidade de oxigênio dissolvido disponível no corpo d'água.

\section{OBJETIVO}

O presente trabalho se propôs a analisar os parâmetros temperatura, turbidez e pH na água do Córrego das Marrecas no município de Dracena - SP.

\section{METODOLOGIA}

O Córrego das Marrecas analisado no presente estudo tem sua nascente no município de Dracena, São Paulo e sua foz no Rio Paraná, na cidade de Panorama - SP como mostra a Figura 1. Em suas margens foram identificado $s$ desmatamentos da vegetação nativa, erosão do solo e despejo de resíduos sólidos com indícios de lixiviação. 


\section{ANAP

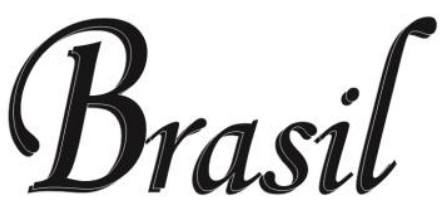 \\ ISSN 1984-3240 V. 12, n. 24}

\section{REVISTA CIENTÍFICA 2019}

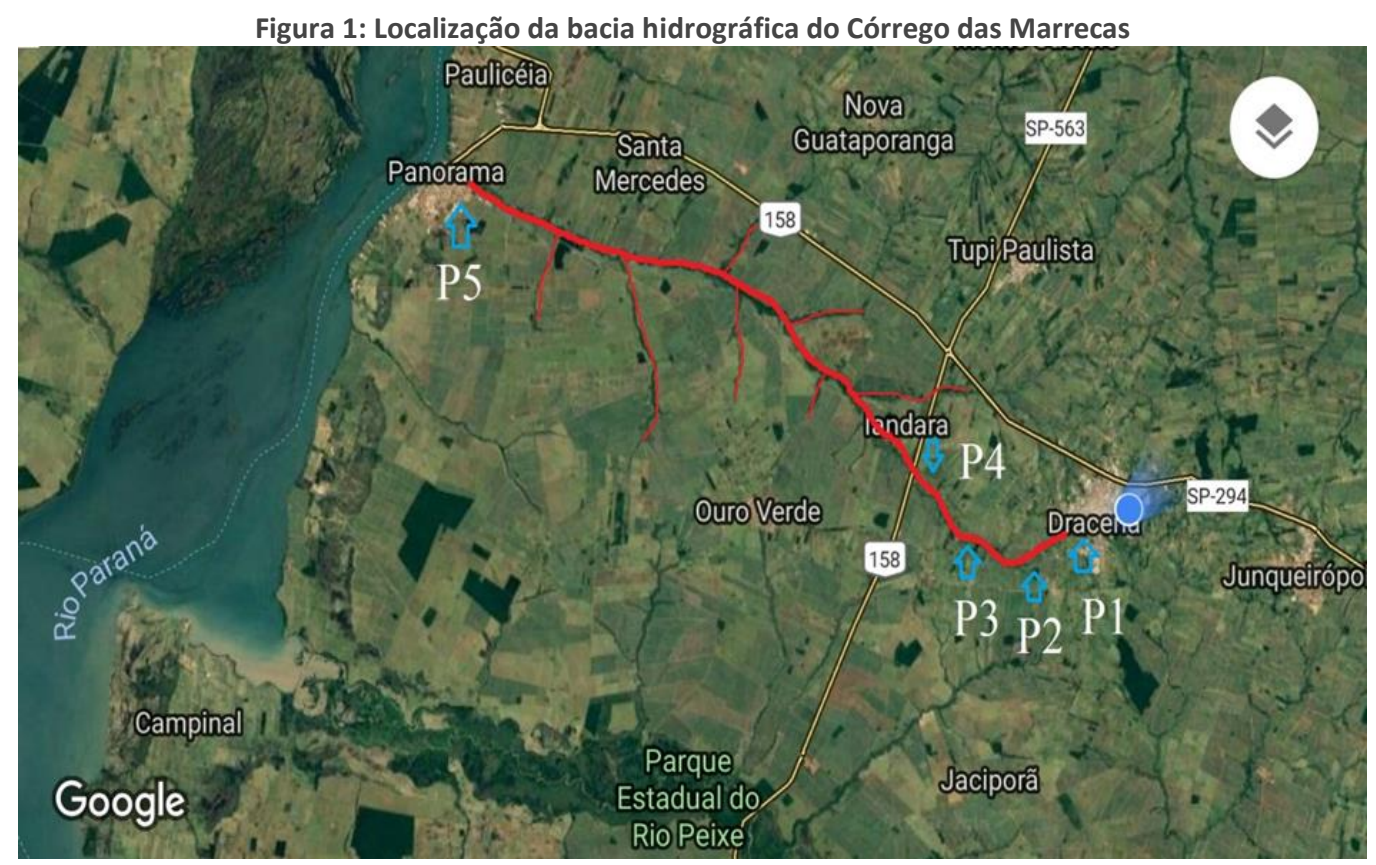

Fonte: GOOGLE MAPS (2018).

As coletas das amostras foram realizadas durante 4 meses, de abril de 2017 a julho de 2017, nos seguintes pontos: P1- nascente do Córrego das Marrecas, situada no perímetro urbano e canalizada paralelamente com a tubulação de água residuária até o término do perímetro urbano, P2- ponto antes do lançamento do efluente tratado da estação de tratamento de esgoto (ETE) do município de Dracena, P3- no lançamento do efluente tratado da ETE de Dracena, P4- ponto a jusante do lançamento da ETE de Dracena, P5- foz do Córrego das Marrecas (Tabela 1).

Tabela 1: Descrição dos pontos de amostragem do Córrego das Marrecas no município de Dracena - SP e suas respectivas coordenadas geográficas.

\begin{tabular}{|c|c|c|c|}
\hline \multirow{2}{*}{$\begin{array}{c}\text { Pontos de } \\
\text { Amostragem }\end{array}$} & \multirow{2}{*}{ Descrição da Localização } & \multicolumn{2}{|c|}{ Coordenadas Geográficas } \\
\hline & & Latitude & Longitude \\
\hline P1 & Nascente do córrego das Marrecas & $\mathrm{S} 21^{\circ} 29^{\prime} 27,7^{\prime \prime}$ & W $51^{\circ} 32^{\prime} 18,1^{\prime \prime}$ \\
\hline P2 & Antes do lançamento de efluente tratado da ETE & $\mathrm{S} 21^{\circ} 29^{\prime} 52,4^{\prime \prime}$ & W $51^{\circ} 33^{\prime} 19,9^{\prime \prime}$ \\
\hline P3 & Lançamento do efluente tratado da ETE & $\mathrm{S} 21^{\circ} 30^{\prime} 11,8^{\prime \prime}$ & W $51^{\circ} 33^{\prime} 53,4^{\prime \prime}$ \\
\hline P4 & Jusante da ETE & $\mathrm{S} 21^{\circ} 29^{\prime} 19,5^{\prime \prime}$ & W $51^{\circ} 36^{\prime} 46,2^{\prime \prime}$ \\
\hline P5 & Foz do córrego das Marrecas & $\mathrm{S} 21^{\circ} 21^{\prime} 04,2^{\prime \prime}$ & W $51^{\circ} 51^{\prime} 05,0^{\prime \prime}$ \\
\hline
\end{tabular}

Em cada ponto foi coletado $1 \mathrm{~L}$ de água superficial, cujas amostras foram armazenadas em frascos âmbar previamente lavados e secos à temperatura ambiente. As amostras foram transportadas em caixas térmicas contendo gelo para serem analisadas no Laboratório de Saneamento da Faculdade de Engenharia de Ilha Solteira. Os métodos utilizados para a realização das análises dos parâmetros são apresentados na Tabela 2. 
Tabela 2: Variáveis analisadas, métodos adotados nas análises laboratoriais e equipamentos utilizados.

\begin{tabular}{cccc}
\hline Parâmetro & Método & Precisão & Equipamentos \\
\hline Temperatura $\left({ }^{\circ} \mathrm{C}\right)$ & Eletrométrico & 0,1 & Sonda Multiparamétrica \\
$\mathrm{pH}$ & Eletrométrico & 0,01 & pHmetro \\
Turbidez (UT) & Nefelométrico & 0,01 & Turbidímetro \\
\hline
\end{tabular}

4 RESULTADOS E DISCUSSÃO

Os valores de turbidez, pH e temperatura no Córrego das Marrecas no município de Dracena SP para os meses de abril a julho de 2017 estão expressos na Tabela 3, 4 e 5, respectivamente.

Tabela 3: Resultado das análises do parâmetro turbidez (UT) no Córrego das Marrecas, durante o período de Abril

\begin{tabular}{cccccccc}
\multicolumn{7}{c}{ a Setembro de 2017. } \\
\hline $\begin{array}{c}\text { Parâmetro } \\
\text { analisado }\end{array}$ & $\begin{array}{c}\text { Pontos de } \\
\text { Amostragem }\end{array}$ & Abril & Maio & Junho & Julho & Agosto & Setembro \\
\hline \multirow{4}{*}{ Turbidez } & P1 & 13,10 & 18,00 & 19,00 & 15,00 & 38,00 & 50,00 \\
& P2 & 13,80 & 55,00 & 17,00 & 17,00 & 18,00 & 10,00 \\
& P3 & 57,00 & 58,00 & 62,00 & 89,00 & 70,00 & 123,00 \\
& P4 & 16,70 & 21,00 & 16,00 & 12,00 & 24,00 & 40,00 \\
& P5 & 14,00 & 17,00 & 13,00 & 18,00 & 19,00 & 14,00 \\
\hline
\end{tabular}

P1: Nascente do córrego das Marrecas; P2: Antes do lançamento de efluente tratado da ETE; P3: Lançamento do efluente tratado da ETE; P4: Jusante da ETE; P5: Foz do córrego das Marrecas;

A Resolução CONAMA no 357/05 estabelece um limite para turbidez de 100 UT. A turbidez da água manteve-se bastante abaixo do limite estabelecido pela legislação durante todos os meses estudados, exceto no ponto 3, na análise realizada no mês de setembro quando o resultado esteve acima do permitido na Resolução CONAMA com um valor de 123 UT. Apesar das demais análises feitas no ponto 3 ficarem abaixo do limite estabelecido na legislação os valores ainda foram superiores ao demais pontos. Este fato pode ser explicado pelo lançamento do efluente da estação de tratamento de esgoto do município de Dracena-SP, uma vez que a turbidez representa o grau de interferência na passagem da luz através da água, conferindo uma aparência turva à mesma (SPERLING, 1996). Pinto (2013) enfatiza que efluentes provocam aumento de turbidez devido a partículas orgânicas e inorgânicas que ele transporta, sólidos suspensos e microrganismos como bactérias e algas. 


\section{ANAP

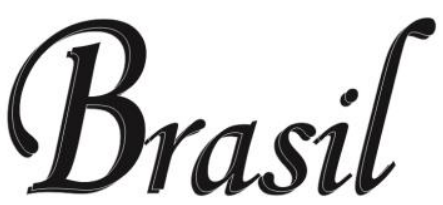 \\ ISSN $1984-3240$ V. 12, n. 24}

\section{REVISTA CIENTÍFICA}

Tabela 4: Resultado das análises do parâmetro pH no Córrego das Marrecas, durante o período de Abril a Setembro de 2017.

\begin{tabular}{cccccccc}
\hline $\begin{array}{c}\text { Parâmetro } \\
\text { analisado }\end{array}$ & $\begin{array}{c}\text { Pontos de } \\
\text { Amostragem }\end{array}$ & Abril & Maio & Junho & Julho & Agosto & Setembro \\
\hline \multirow{4}{*}{ PH } & P1 & 7,24 & 7,63 & 6,92 & 7,35 & 7,40 & 7,69 \\
& P2 & 7,62 & 7,80 & 6,75 & 7,58 & 7,63 & 7,79 \\
& P3 & 7,05 & 7,10 & 6,79 & 7,43 & 7,62 & 7,50 \\
& P4 & 7,57 & 7,40 & 6,18 & 7,53 & 7,39 & 7,65 \\
& P5 & 7,33 & 7,04 & 6,78 & 7,49 & 7,53 & 7,35 \\
\hline
\end{tabular}

P1: Nascente do córrego das Marrecas; P2: Antes do lançamento de efluente tratado da ETE; P3: Lançamento do efluente tratado da ETE; P4: Jusante da ETE; P5: Foz do córrego das Marrecas;

A Resolução CONAMA no 357/05 estabelece que o pH deve ser entre 6,0 a 9,0 quando se trata de águas doces de classe 2 como é o caso do córrego das Marrecas. De acordo com os valores obtidos, todos os resultados atenderam a legislação. Segundo Esteves (2011), o pH pode ser considerado como uma das variáveis ambientais mais importantes nos ecossistemas aquáticos. Para a manutenção da vida aquática Libânio (2010) diz que o valor adequado do pH deve estar entre 6,0 a 8,5 e os resultados obtidos também atendem essa exigência. Bernardi (2018) constatou que em meses mais secos o pH tende a diminuir, esse fato pode explicar os resultados do mês de junho quando os valores do $\mathrm{pH}$ ficaram abaixo de 7.

Tabela 5: Resultado das análises do parâmetro temperatura $\left({ }^{\circ} \mathrm{C}\right)$ no Córrego das Marrecas, durante o período de Abril a Setembro de 2017.

\begin{tabular}{cccccccc}
\hline $\begin{array}{c}\text { Parâmetro } \\
\text { analisado }\end{array}$ & $\begin{array}{c}\text { Pontos de } \\
\text { Amostragem }\end{array}$ & Abril & Maio & Junho & Julho & Agosto & Setembro \\
\hline \multirow{5}{*}{ Temperatura } & P1 & 24,30 & 22,85 & 21,88 & 20,00 & 22,90 & 23,15 \\
& P2 & 25,88 & 23,30 & 21,00 & 22,35 & 21,00 & 23,20 \\
& P3 & 27,20 & 24,20 & 20,30 & 24,25 & 21,70 & 25,70 \\
& P4 & 25,60 & 22,40 & 20,08 & 22,08 & 21,35 & 24,98 \\
& P5 & 26,45 & 22,67 & 21,50 & 20,10 & 21,10 & 24,35 \\
\hline
\end{tabular}

P1: Nascente do córrego das Marrecas; P2: Antes do lançamento de efluente tratado da ETE; P3: Lançamento do efluente tratado da ETE; P4: Jusante da ETE; P5: Foz do córrego das Marrecas;

Bernardi (2018) afirma que em períodos secos a temperatura tende a ser menor do que em períodos chuvosos. O mês de abril é caracterizado pelo fim do período chuvoso, por isso teve as maiores temperaturas entre os meses analisados. A afirmação feita por Bernardi (2018) é constatada através dos resultados dos meses de maio, junho, julho e agosto, pois são meses considerados secos ou com pouca chuva, com isso ocorre uma diminuição da temperatura. 0 período chuvoso se inicia no mês de outubro, mas a elevação da temperatura pode ser constatada já no mês de setembro com base nos resultados obtidos nas análises desta pesquisa. 


\section{CONCLUSÃo}

A avaliação do Córrego das marrecas no município de Dracena - SP em relação ao parâmetro turbidez demonstrou que os resultados se mantiveram abaixo do determinado pela Resolução CONAMA porém é necessário continuar o monitoramento para verificar se o resultado discrepante obtido no ponto 3 no mês de setembro foi um episódio isolado ou um valor que começaria a ser comum em futuras análises.

Os valores de $\mathrm{pH}$ também se mantiveram dentro da Resolução CONAMA, mas o monitoramento continuo do parâmetro poderá evidenciar se no período chuvoso os valores tenderiam a aumentar, constatando qual a faixa de variação sazonal do $\mathrm{pH}$, permitindo assim verificar se essa variação poderia estar afetando algum organismo ou reação química.

Os valores de temperatura obtidos podem ser considerados normais de acordo com a Resolução CONAMA. A necessidade de monitorar os valores dos resultados do parâmetro temperatura da água na estação chuvosa é de suma importância para verificar a variação sazonal, uma vez que a temperatura tem reflexos sobre a vida aquática, As elevações de temperatura aumentam a taxa das reações químicas e biológicas, aumenta também a taxa de transferência dos gases, o que pode causar mau cheiro e diminuem a solubilidade dos gases.

Portanto, o monitoramento dos parâmetros analisados deve continuar para constatar as variações que podem ocorrer em um período de tempo maior.

\section{REFERÊNCIAS BIBLIOGRÁFICAS}

BARRETO, L.V.; FRAGA, M. de S.; BARROS, F. M.; ROCHA, F. A.; AMORIM, J. da S.; CARVALHO, S. R.; BONOMO, P.; SILVA, D. P. Estado trófico em uma seção do rio Catolé Grande sob diferentes níveis de vazão. Revista Ambiente \& Água, Taubaté, v. 9, n. 2, p.250-260, jul. 2013.

BERNARDI, I.. Avaliação e monitoramento da qualidade da água em pisciculturas em tanques-rede em um braço do Rio Grande, no Reservatório de Ilha Solteira/SP. Dissertação de mestrado-UNESP. 101p., 2018.

BRANCO, S. M. Hidrobiologia aplicada à engenharia sanitária. 2.ed. São Paulo:Editora CETESB, 1983.

BRANCO, S. M. Hidrologia aplicada à engenharia sanitária. 3a ed. São Paulo. CETESB/ACATESB. 1986. 640p

CETESB. Significado Ambiental e Sanitário das Variáveis de Qualidade das águas e dos Sedimentos e Metodologias Analíticas de Amostragem. Companhia Ambiental do Estado de São Paulo. São Paulo, p. 44. 2009.

CONSELHO NACIONAL DO MEIO AMBIENTE - CONAMA. Resolução n. 357, de 17 de março de 2005. Dispõe sobre a classificação das águas doces, salobras e salinas do território nacional. Diário Oficial da União, Brasília, 17 mar. 2005. 


\section{ANAP}

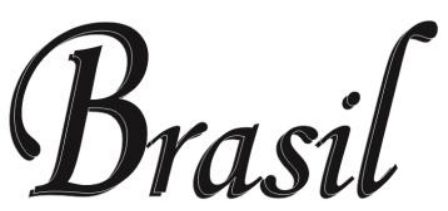

ESTEVES, F.A. (coord). Fundamentos de Limnologia. 3 ed. Rio de Janeiro: Interciência, 2011. $826 \mathrm{p}$.

GOOGLE MAPS. Córrego das Marrecas - SP. Disponível em: <https://www.google.com.br/maps/@21.3913745,51.691251,32279m/data=!3m1!1e3>. Acesso em: 08 jun. 2018.

LIBÂNIO, M. Fundamentos de qualidade e tratamento de água. 3 ed. Campinas, SP: Átomo, 2010.

LIMA, E. B. N. R. Modelagem integrada para gestão da qualidade da água na bacia do Rio Cuiabá. 2001, 184 f. Tese (Doutorado em Ciências em Engenharia Civil) - Universidade Federal do Rio de Janeiro, Rio de Janeiro, 2001.

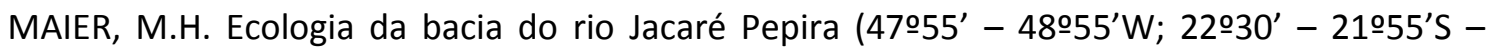
Brasil): qualidade da água do rio principal. Ciência e Cultura, 39(2): 164-185. 1987

PERCEBON, C. M.; BITTENCOURT, C. M.; FILHO, E. F. R.. Diagnóstico da temperatura das águas dos principais rios de Blumenau-SC. Boletim Paranaense de Geociências, n. 56, p. 7-19, 2005.

PINTO, A. H. Remoção de turbidez em esgoto doméstico utilizando coagulante orgânico. Pós Graduação em Gestão Ambiental. UTFPR, 27p., 2013.

RODRIGUES JUNIOR, F.. Diagnóstico da influência de atividades antrópicas na qualidade da água do córrego Gavanhery no município de Getulina - SP. Dissertação de Mestrado, Faculdade de Engenharia - UNESP - Ilha Solteira, 2008.

SILVA, M. A.; ARAÚJO, R. R.. Revista FORMAÇÃO (ONLINE). Vol. 1; n. 24, Jan-Abril/2017; p. 182-203.

SPERLING, M. V.. Introdução à qualidade das águas e ao tratamento de esgotos. 2a Ed., - Belo Horizonte: Departamento de Engenharia Sanitária e Ambiental; Universidade Federal de Minas Gerais; 1996. 